\title{
Kolorektal kanserli hastaların asemptomatik birinci derece yakınlarının kolonoskopik değerlendirme sonuçları: Tek merkezli prospektif çalışma
}

Colonoscopic assessment results of asymptomatic first-degree relatives of patients with colorectal cancer: A single center prospective study

Bilal ERGÜL, Murat SARIKAYA, Zeynal DOĞAN, Levent FILIIK

Ankara Eğitim ve Araştırma Hastanesi, Gastroneteroloji Bölümü, Ankara

\begin{abstract}
Giriş ve Amaç: Kolorektal kanserli hastaların birinci derece akrabalarnnda kolorektal neoplazm gelişme riski artmıștır, mevcut kılavuzlar bu bireylerde kolonoskopik tarama yapılmasını önermektedir. Çalışmamızın amacı, kolorektal kanserli hastaların asemptomatik birinci derece yakınlarında kolonoskopik tarama sonuçlarının değerlendirmektir. Gereç ve Yöntem: En az bir birinci derece akrabasinda kolorektal kanser öyküsü olan toplam 80

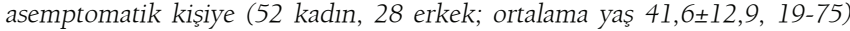
kolonoskopi yapıldı. Çalışmaya alınma kriterleri olarak; asemptomatik, 40 yaşından büyük veya indeks vakadan en fazla 10 yas küçük olması olarak belirlendi. Bulgular: Toplam 22 hastada 36 kolorektal lezyon tespit edildi: 2 hastada (\%5,5) adenokarsinom ve kalan 20 hastada 34 polipoid lezyon saptand1: 19'u (52,7\%) düșük riskli adenom, 10'u (27,8\%) yüksek riskli adenom ve 5 (13,9\%) hastada hiperplastik polip. Işlem tüm hastalarda komplikasyon olmadan çok iyi şekilde tolere edildi. Tartışma: Kolonoskopik tarama, kolorektal kanserli hastaların birinci derece yakınlarında polip ve adenokarsinom saptanmasinda etkili ve güvenlidir.
\end{abstract}

Anahtar Kelimeler: Kolonoskopik tarama, birinci derece akraba, kolorektal kanser, polip

\section{GİRISş}

Kolorektal kanser, gelişmiş ülkelerde kansere bağlı ölümler arasında 2. sirada yer almaktadır (1). Kolorektal kanser gelişen vakalarda \%20-25 oranın aile öyküsü mevcuttur. Birinci derece yakınında, herediter non-polipozis kolorektal kanser ve familyal adenomatöz polipozis koli gibi genetik sendromlar haricinde kolorektal kanser öyküsü olanlarda, normal popülasyona göre kolon kanseri gelişme riski 2-4 kat artmaktadır (2). Kolorektal kanserin ortaya çıktığı yaş, görülen akraba sayısı ve yakınlığı, hastalığın oluşumu için temel risk faktörleridir (3). Illeri evre adenomatöz lezyon ( $\geq 10 \mathrm{~mm}$ adenom, villöz komponent veya ağır displazi) saptananlarda, yıllık kanser gelişim riski \%2.6-5.7 oranındadır (3). Pozitif aile öyküsü olan bireylerde kolonoskopik tarama yapılarak saptanan poliplerin çıkarılması ile kolorektal kanser insidansı ve mortalitesinde azalma olduğu gösterilmiştir (4). Bu yüzden birçok ülkede sigmoidoskopi ve gaitada gizli kan ölçülmesi yerine, kolonoskopi ile tarama programları uygulanmaktadır. Yaygın kabul gören tedavi kılavuzları Amerikan Gastroente-
Background and Aims: First-degree relatives of colorectal cancer patients are at increased risk of developing colorectal neoplasm, and current guidelines recommend a screening colonoscopy in such individuals. The aim of this study was to evaluate the use of total colonoscopy as the screening test in asymptomatic first-degree relatives of colorectal cancer patients. Materials and Methods: Colonoscopy was performed in 80 asymptomatic individuals (52 females, 28 males; mean age 41,6 $\pm 12,9$ years, range 19-75 years) who had at least one first-degree relative with colorectal cancer. As inclusion criteria, subjects had to be asymptomatic, older than 40 years, or less than 10 years younger than the index case. Results: Thirty-six colorectal lesions were found in 22 individuals: 2 (5,5\%) had adenocarcinomas and the remaining $20 \mathrm{pa}-$ tients had 34 polypoid lesions [19 (52,7\%) low-risk adenomas, 10 (27,8\%) high-risk and 5 (13,9\%) hyperplasic polyps]. The procedure was generally well tolerated without complications. Conclusions: Screening colonoscopy is safe and effective to detect adenoma and adenocarcinoma among asymptomatic first-degree relatives of patients with colorectal cancer.

Keywords: Screening colonoscopy, first-degree relatives, colorectal cancer, polyp

roloji Kolleji (ACG) (5), Amerikan Gastrointestinal Endoskopi Derneği (ASGE) (6) ve Amerikan Gastroenteroloji Birliği (AGA) (7) genel olarak 60 yaşından önce kolon kanseri görülen hastaların birinci derece yakınlarına 40 yaşından sonra 5 yılda bir kolonoskopi taraması önermektedir. 60 yaşından sonra saptananların birinci derece yakınlarına ise, ASGE ve AGA 40 yaşından sonra, ACG ise 50 yaşından sonra kolon taraması önermektedir.

Kolon kanseri gelişiminde yaş, genetik faktörler, aile öyküsünün yanı sıra diyet, coğrafi bölge gibi değişkenler de etkili olmaktadır. Biz bu çalışmada, birinci derece yakınında kolon kanseri olan asemptomatik bireylerin kolonoskopi sonuçları ile ilgili ülkemizden yayınlanmış bir çalışma olmadığından, bölgemizdeki bulguları ortaya koymayı amaçladık.

\section{GEREÇ VE YÖNTEM}

Çalışmamız Ocak 2011- Aralık 2012 tarihleri arasında Ankara Eğitim ve Araştırma Hastanesi Gastroenteroloji Bölü- 
münde yapildı. Kolonoskopi işlemi esnasında kolon kanseri tanısı konulan hastaların 1. derece yakınlarına kolonoskopi yapılması önerildi. Ayrıca başka bir nedenden poliklinik muayenesine gelen hastalar, 1. derece yakınında kolon kanseri varlığı açısından sorgulandı, pozitif aile öyküsü olanlara kolonoskopik inceleme tavsiye edildi. Çalışmaya alınma kriterleri olarak; asemptomatik, 40 yaşından büyük veya indeks vakadan en fazla 10 yaş küçük olması belirlendi. Daha önceden bilinen gastrointestinal sisteme ait kanser veya kronik inflamatuvar hastalı̆ıı olanlar, son 5 yll içinde tarama amaçlı kolonoskopi yaptıranlar, kolonoskopik inceleme yapılan ancak yetersiz temizlik nedeniyle işlemin optimal olmadığ vakalar çalışma dışı bırakıldı. Hastalara midazolam+fentanil ile sedasyon eşliğinde kolonoskopi yapıldı. Hastaların yaşları, cinsiyetleri, kolonoskopi bulguları, polip sayısı, büyüklüğü ve lokalizasyonu, patolojik sonuçları not edildi. Patolojik bulgular adenokarsinom, yüksek riskli adenom $(\geq 10 \mathrm{~mm}$ ve/ veya villöz komponent içermesi) ve düşük riskli adenom (tübüler adenom <10 mm) şeklinde sınıflandırıldı.

Çalışmadaki verilerin analizinde SPSS 15.0 for Windows (SPSS, Inc, Chicago, IL, USA) programı kulanılmıştır. Verilerin değerlendirilmesinde tanımlayıcı istatistiksel yöntemlerin yanı sıra grupların karşılaştırılması için student-t testi ve Ki-kare testi kullanılmıştır.

\section{BULGULAR}

Çalışmaya 52'si kadın, 28'i erkek olmak üzere toplam 80 hasta dahil edildi. Hastaların ortalama yaşları 46,3 $\pm 12,9$ (19-75) idi. Vakaların 64'ünün anne-babasında, 15'inin kardeşinde kolon kanseri öyküsü mevcuttu. Hastaların ayrıntılı karakteristik bulguları Tablo l'de görülmektedir.

Tablo 1: Çalışmaya dahil edilen 80 hastanın karakteristik bulgular1

\begin{tabular}{|lc|}
\hline Hasta karakteristikleri & Sayı \\
\hline Cinsiyet & Toplam \\
\hline Erkek & $28(\% 35)$ \\
\hline Kadın & $52(\% 65)$ \\
\hline Yaş & $46,3(19-75)$ \\
\hline Yaş grupları & \\
\hline$<40$ yaş & $27(\% 33,8)$ \\
\hline $40-49$ yaş & $20(\% 25,0)$ \\
\hline $50-59$ yaş & $21(\% 26,2)$ \\
\hline$\geq 60$ yaş & $12(\% 15,0)$ \\
\hline Indeks vakaya yakınlık & \\
\hline Baba & $39(\% 48,8)$ \\
\hline Anne & $25(\% 31,2)$ \\
\hline Kardeş & $15(\% 18,8)$ \\
\hline Çocuk & $1(\% 1,2)$ \\
\hline Toplam & $80(\% 100)$ \\
\hline
\end{tabular}

Hastaların 58'inde $(\% 72,5)$ normal kolonoskopik bulgular saptanırken, 2 (\%2,5) hastada adenokarsinom, 20 (\%25) hastada da kolon polipleri saptand. Bu 22 hastada toplam 36 neoplastik veya düşük neoplastik riskli polip bulundu. Tespit edilen poliplerden $10 \mathrm{~mm}$ ve daha büyük olanların 7'si (7/12) histolojik olarak malignite veya villöz komponent içerirken, 10 mm'den küçük poliplerin sadece l'i (1/24) villöz histoloji içermekteydi (Tablo 2). Toplam 11 hastada (\%13,7) ileri evre neoplastik lezyon saptandı. Adenokarsinom ve yüksek riskli polip saptanan hastalar ile düşük riskli polip saptanan hastaların ayrınitlı özellikleri Tablo 3'de mevcuttur. Lezyonların büyük kısmı sol kolonda lokalize iken (28/36), sağ kolonda sadece 1 vakada polip saptand. Kolonoskopik inceleme ile

Tablo 2. Kolonoskopi yapilan hastalarda saptanan lezyonların lokalizasyonu ve histolojik bulguları

\begin{tabular}{|lc|}
\hline Kolonoskopik bulgular & Sayı (\%) \\
\hline Neoplastik lezyon & $12(\% 33,3)$ \\
\hline Kanser & $2(\% 5,5)$ \\
\hline Yüksek riskli adenom & $10(\% 27,8)$ \\
\hline Villöz veya tübülovillöz adenom & $6(\% 16,7)$ \\
\hline Tübüler adenom $\geq 10 \mathrm{~mm}$ & $4(\% 11,1)$ \\
\hline Düşük riskli lezyon & $24(\% 66,6)$ \\
\hline Düşük riskli adenom & $19(\% 52,7)$ \\
\hline Hiperplastik & $5(\% 13,9)$ \\
\hline Toplam & $36(\% 100)$ \\
\hline Lezyonların lokalizasyonu & \\
\hline Rektosigmoid & $20(\% 55,5)$ \\
\hline Inen kolon & $8(\% 22,2)$ \\
\hline Transvers kolon & $7(\% 19,5)$ \\
Sağ kolon & $1(\% 27,8)$ \\
\hline
\end{tabular}

Tablo 3. Düşük ve yüksek riskli lezyon saptanan hastaların özelikleri

\begin{tabular}{|lccc|}
$\begin{array}{l}\text { Hasta } \\
\text { karakteristikleri }\end{array}$ & $\begin{array}{c}\text { Düşük riskli } \\
\text { lezyon(n) }\end{array}$ & $\begin{array}{c}\text { Yüksek riskli } \\
\text { lezyon(n) }\end{array}$ & Toplam \\
\hline Cinsiyet & 22 & 6 & 28 \\
\hline Erkek & 47 & 5 & 52 \\
\hline Kadın & & & \\
\hline Yakınlık & 55 & 9 & 64 \\
\hline Anne-baba & 13 & 2 & 15 \\
\hline Kardeş & 1 & 0 & 1 \\
\hline Çocuk & & & \\
\hline Yaş grubu & 24 & 3 & 27 \\
\hline$<40$ & 18 & 2 & 20 \\
\hline $40-49$ & 18 & 3 & 21 \\
\hline $50-59$ & 9 & 3 & 12 \\
\hline T60 & & & $\mathbf{8 0}$ \\
\hline Toplam & & & \\
\hline
\end{tabular}


saptanan poliplerin lokalizasyonu ve histolojik özellikleri ayrıntılı olarak Tablo 2'de görülmektedir.

\section{TARTIŞMA}

Kolonoskopi, birinci derece akrabasinda kolon kanseri olan bireylerde yaygin olarak kullanılan bir tarama yöntemidir. Bu çalışmada, tarama programına katılan toplam 80 hastanın \%27,5'inde kolonda lezyon saptanmıştır. Literatürde asemptomatik birinci derece yakınların tarama programlarında $\% 16,7, \% 28,8, \% 36,1$ gibi farklı oranlarda patolojik bulgulara rastlanmıştır (8-10).

Ileri evre neoplastik lezyon, çalışmaya katılan hastaların $\% 13,7$ 'sinde bulundu. Bu oran, kolon kanserli hastalarm birinci derece akrabalarında kanser gelişme riskinin arttı̆̆ bilgisini desteklemektedir. Pariente ve arkadaşlarının yaptığı vaka-kontrollü çalışmada, ileri evre neoplastik lezyon gelişme riskinin birinci derece akrabalarda 2,6 kat arttığını göstermiştir (11). Son yıllarda Armelao ve arkadaşlarının yaptığı iki büyük çalışmada, birinci derece akrabalarda ileri evre neoplastik lezyon görülme oranları \%8,8 ve \%11,3 olarak bulunmuştur $(12,13)$. Yine bu çalışmada multivaryant analiz sonucunda kontrol gruba göre küçük polip görülme riski artmazken, ileri evre neoplastik polip görülme riskinde 2,4 kat artış saptanmıştır (13).

\section{KAYNAKLAR}

1. Parkin DM, Bray F, Ferlay J, Pisani P. Global cancer statistics, 2002. CA Cancer J Clin 2005; 55: 74-108.

2. Johns LE, Houlston RS. A systematic review and meta-analysis of familial colorectal cancer risk. Am J Gastroenterol 2001; 96: 2992-3003.

3. Brenner H, Hoffmeister M, Stegmaier C, et al. Risk of progression of advanced adenoma to colorectal cancer by age and sex: estimates based on 840149 screening colonoscopies. Gut 2007; 56: 1585-9.

4. Dove-Edwin I, Sasieni P, Adams J, et al. Prevention of colorectal cancer by colonoscopic surveillance in individuals with a family history of colorectal cancer: 16 year, prospective, follow-up study. BMJ 2005; 331: 1047-9.

5. Levin B, Lieberman DA, McFarland B, et al. Screening and surveillance for the early detection of colorectal cancer and adenomatous polyps, 2008: a joint guideline from the American Cancer Society, the US MultiSociety Task Force on Colorectal Cancer, and the American College of Radiology. Gastroenterology 2008; 134: 1570-95.

6. Rex DK, Johnson DA, Anderson JC, et al. American College of Gastroenterology guidelines for colorectal cancer screening 2009. Am J Gastroenterol 2009; 104: 739-50.

7. Davila RE, Rajan E, Baron TH, et al. ASGE guideline: colorectal cancer screening and surveillance. Gastrointest Endosc 2006; 63: 546-57.

8. Maxim M, Trifan A, Stanciu C. Colonoscopic screening of asymptomatic individuals with a family history of colorectal cancer. Rev Med Chir Soc Med Nat Iasi 2010; 114: 993-7.

9. Croitoru L, Trifan A, Maxim MR, et al. Colonoscopic screening of asymptomatic first-degree relatives of colorectal cancer patients. Rev Med Chir Soc Med Nat Iasi 2010; 114: 683-6.
Ileri evre neoplastik lezyon görülme riski yaşla birlikte artmaktadır (14). Bizim çalışmamızda, 40 yaşından küçüklerde ileri evre neoplastik lezyon saptanma oranı \%11,1 olurken, 40 yaşın üzerindekilerde \% 15,1 olarak bulundu. Gutiérrez ve arkadaşlarının 263 hastalık serisinde bu oran 40 yaşın altında $\% 10,8$ iken, $40-44$ yaş grubunda \% $16,4,45-49$ yaş grubunda $\% 20,9$ ve 60 yaş üzerinde \%25,4 olarak saptanmıştır (10). Blanco ve arkadaşlarının yenilerde yaptı̆̆ı bir çalışmada, kolorektal kanserli hastalarm asemptomatik birinci derece yakınlarında 40-50, 50-60 ve 60-70 yaş gruplarında adenom ve ileri evre neoplastik lezyon görülme sıklıkları açısından fark saptanmamış ve 40 yaşından sonra bu grupta tarama programına başlanması önerilmiştir (15). 640 vakalık geniş bir seride 40-45 yaş grubundaki adenom saptanma riskinin 4550 yaş grubunda belirgin olarak daha da arttığı gösterilmiştir (16). Bu durum 60 yaşından önce kolorektal kanser saptanan hastaların 1. derece akrabalarında tarama programının 5 yılda bir yapılması gerekliliğini desteklemektedir.

Sonuç olarak, pozitif aile öyküsü kolorektal kanser gelişiminde çok iyi tanımlanmış bir risk faktörüdür. Çalışmamızda saptadığımız, yüksek riskli adenom ve adenokarsinom oranları literatürle genel olarak uyumlu bulunmuştur. Kolon kanseri insidansını düşürmek ve mortaliteyi azaltmak için, pozitif aile öyküsü olan bireyler 40 yaşından sonra veya indeks vakadan 10 yaş önce olacak şekilde tarama programına alınmalıdır.

10. Puente Gutiérrez JJ, Marín Moreno MA, Domínguez Jiménez JL, et al. Effectiveness of a colonoscopic screening programme in first-degree relatives of patients with colorectal cancer. Colorectal Dis 2011; 13: el45-53.

11. Pariente A, Milan C, Lafon J, Faivre J. Colonoscopic screening in firstdegree relatives of patients with 'sporadic' colorectal cancer: a case-control study. Gastroenterology 1998; 115: 7-12.

12. Armelao F, Orlandi PG, Tasini E, et al. High uptake of colonoscopy in first-degree relatives of patients with colorectal cancer in a healthcare region: a population-based, prospective study. Endoscopy 2010; 42: 1521.

13. Armelao F, Paternolli C, Franceschini G, et al. Colonoscopic findings in first-degree relatives of patients with colorectal cancer: a populationbased screening program. Gastrointest Endosc 2011; 73: 527-534.e2.

14. Baglietto L, Jenkins MA, Severi G, et al. Measures of familial aggregation depend on definition on family history: metaanalysis for colorectal cancer. J Clin Epidemiol 2006; 59: 114-24.

15. Blanco GD, Cretella M, Paoluzi OA, et al. Adenoma, advanced adenoma and colorectal cancer prevalence in asymptomatic 40 to 49 -year-olds with a first-degree family history of colorectal cancer. Colorectal Dis. 2013 Apr 30. [Epub ahead of print]

16. Gupta AK, Samadder J, Elliott E, et al. Prevalence of any size adenomas and advanced adenomas in 40- to 49-year-old individuals undergoing screening colonoscopy because of a family history of colorectal carcinoma in a first-degree relative. Gastrointest Endosc 2011; 74: 110-8. 